\title{
Aminotransferase Changes and Acute Hepatitis in Patients With Dengue Fever: Analysis of 1,585 Cases
}

Luiz José de Souza ${ }^{1,2}$, José Galvão Alves², Rita Maria Ribeiro Nogueira ${ }^{3}$, Carlos Gicovate Neto ${ }^{1,2}$, Diogo Assed Bastos ${ }^{1,2}$, Edno Wallace da Silva Siqueira ${ }^{1,2}$, João Tadeu Damian Souto Filho ${ }^{1,2}$, Thiago de Abreu Cezário ${ }^{1,2}$, Carlos Eduardo Soares ${ }^{1,2}$ and Rodrigo da Costa Carneiro ${ }^{1,2}$

\author{
Dengue Reference Center ${ }^{l}$; The Brazilian Society of \\ Internal Medicine ${ }^{2}$, Campos dos Goytacazes; \\ Department of Virology, Oswaldo Cruz Institute, \\ FIOCRUZ , Rio de Janeiro, RJ, Brazil
}

\begin{abstract}
Introduction: Type 3 dengue virus caused an extensive epidemic in the state of Rio de Janeiro in summer 2002. In some of the patients, it was found in an atypical form with increased aminotransferase levels and acute hepatitis. Material and Methods: An analysis was made of 1,585 serologically confirmed dengue cases at the Dengue Reference Center in Campos dos Goytacazes, Rio de Janeiro state. The grade of hepatic aggression was established according to the alterations in the aminotransferase levels: grade $\mathrm{A}$ - normal levels of aminotransferase; grade B - elevated aminotransferase, with increased levels of at least one of the enzymes; grade C elevated aminotransferase, with the levels of at least one of the enzymes increased to more than three times the reference values; grade $D$ - acute hepatitis, with aminotransferase levels increased to at least 10 times their normal values. Results: Among the 1,585 serologically confirmed dengue cases, $44.5 \%$ presented alterations in the aminotransferase levels (grade B), $16.9 \%$ presented grade $\mathrm{C}$ liver involvement and $3.8 \%$ of the patients had progressed to acute hepatitis (grade D). The average values for the rise in aspartate aminotransferase and alanine aminotransferase were $93.3 \mathrm{U} / \mathrm{L}$ and $86.0 \mathrm{U} / \mathrm{L}$. The greatest alterations were observed among females $(p<0.001)$, cases of dengue hemorrhagic fever $(p<0.001)$, and cases with sequential infections ( $p=0.001)$. Conclusions: Liver damage with elevation of aminotransferases and reactive hepatitis was a common complication of dengue virus infection in these patients.

Key Words: Dengue fever, aminotransferase, hepatic injury.
\end{abstract}

Dengue fever is an acute infectious disease caused by an arbovirus in the Flavivirus genus. It has four serotypes, and the mosquito Aedes aegypti is the vector. It is the most common arbovirosis in the world, and is also the most important one in terms of morbidity and mortality. [1-8]. In the state of Rio de Janeiro, there have been epidemics in different regions since the outbreak of type 1 dengue in 1986 and type 2 in

Received on 17 October 200X; revised 23 March 2004.

Address for correspondence: Dr. Luiz José de Souza. Sociedade Brasileira de Clínica Médica / RJ. Avenida Alberto Torres, 217 - Centro. Zip code: 28035-580. Campos dos Goytacazes - Rio de Janeiro - Brazil Telephone/fax number: (22) 27239243.

E-mail: sbcm.rol@terra.com.br

The Brazilian Journal of Infectious Diseases 2004;8(2):156-163 (C) 2004 by The Brazilian Journal of Infectious Diseases and Contexto Publishing. All rights reserved.
1990 [9-11]. Type 3 dengue virus was isolated for the first time in December 2000; it was the cause of the country's most serious dengue epidemic ever, about one year after the initial outbreak [12].

From January to May 2002, the state of Rio de Janeiro was afflicted by a dengue epidemic, with 255,493 notified cases of the disease and 91 fatalities [13]. At this time, the Dengue Reference Center (CRD) was set up in Campos dos Goytacazes for dengue diagnosis, treatment and clinical research.

Over the last few years, atypical manifestations of dengue have been described, including involvement of the central nervous system, cardiac alterations, and elevations in aminotransferase levels, with reactive hepatitis. These manifestations have been observed during epidemics in Brazil [14-16]. The unusual clinical forms of this disease are frequently associated with 
more serious states, and they often result from multifactorial conditions, such as the use of hepatotoxic drugs, in addition to the direct aggression by the dengue virus [6,17-20].

Isolation of type 1 dengue virus from the liver was made by Nogueira et al. [9] in Rio de Janeiro during the 1986 epidemic. Mid-zone and centrilobular necrosis similar to yellow fever was also observed. The detection of the dengue antigen in hepatocytes in another five cases suggests that such cells can support viral replication [21].

Hepatic involvement can be characterized by manifestations of acute hepatitis, with pain in the right hypochondrium, hepatomegaly, jaundice, and raised aminotransferase levels. In hepatitis, the levels of these enzymes reach a maximum on the ninth day after the onset of symptoms, and they gradually return to normal levels within three weeks. Although the liver is not the main target organ for this disease, histopathological findings, including centrilobular necrosis, fatty alterations, hyperplasia of the Kupffer cells, acidophil bodies and monocyte infiltration of the portal tract have been detected in patients with dengue hemorrhagic fever (DHF) and dengue shock syndrome (DSS). In most cases, hepatic involvement prolongs the clinical course of this self-limiting viral infection, but it does not constitute a sign of worse prognosis [4,17-26].

\section{Material and Methods}

Campos dos Goytacazes is a municipality with an area of $4,037.8 \mathrm{~km}^{2}$ located in the northern region of the state of Rio de Janeiro, Brazil, with a population of 363,721 inhabitants. Since the colonial period, it has been characterized by sugar cane cultivation across its broad lowlands, which extend from the Atlantic Ocean to the Serra do Mar (a coastal mountain range), with a hot and humid climate.

\section{Case definition and sample}

Case definition. Patients were included in the study if they had compatible clinical and laboratory states (fever, headache, arthralgia, myalgia, retroorbital pain, nausea, vomiting, prostration, leukopenia, blood hemoconcentration and low platelet count) and were serologically positive for anti-dengue IgM antibodies.

During the period from March to May 2002, 3,850 patients with clinical or laboratory suspicion of the disease were attended at the CRD. The patients were clinically evaluated and included in a laboratory evaluation protocol that depended on the clinical activity of the disease. For symptomatic patients or those attended between the first and the $10^{\text {th }}$ day of symptoms, the protocol included a complete blood count, and aspartate aminotransferase (AST) and alanine aminotransferase (ALT) assays. For asymptomatic patients attended after this period, and for those initially evaluated in other hospitals and referred to the CRD, the serological $\operatorname{IgM}$ and $\operatorname{IgG}$ tests for dengue were requested between the $10^{\text {th }}$ and $14^{\text {th }}$ day of the disease. These were performed using Pan $\mathrm{Bio}^{\circledR}$ rapid strip test kits for qualitative detection of $\mathrm{IgG}$ and $\mathrm{IgM}$ anti-dengue antibodies in human serum (Dengue Duo IgM and the IgG rapid strip test Cat. No. R-DEN02D, Pan Bio ${ }^{\circledR}$, Brisbane, Australia), and were processed in accordance with the manufacturer's instructions.

In the evaluation of the 3,850 patients referred to the CRD, a wide range of differential diagnoses was observed, including hepatitis A, B and C, cytomegalovirosis, infectious mononucleosis, toxoplasmosis, leptospirosis, and other bacterial infections, and one case of acute leukemia. Appropriate treatment for each case was instituted.

After clinical evaluation, the patients with a diagnosis of dengue were given guidance for outpatient follow-up, or were interned in CRD wards. The treatment instituted for these patients was basically symptomatic, with the use of antipyretics, analgesics, antiemetics, and venous hydration with crystalloid solution in the hospital internment cases.

The diagnosis of DHF was established in accordance with World Health Organization criteria, with adaptations: low platelet count $(\leq 100,000 / \mathrm{uL})$, blood hemoconcentration and 
proof of a positive link or other hemorrhagic manifestation. Blood hemoconcentration was defined on the basis of the hematocrit $(\mathrm{Ht})$ values: $\mathrm{Ht}>45 \%$ for men, $\mathrm{Ht}>40 \%$ for women and $\mathrm{Ht}>$ $38 \%$ for children under 12 years [27]. The criteria of a $20 \%$ increase in hematocrit for defining blood concentration was not used since there was no previous data for these patients.

The assessment of the hepatic aggression in the confirmed dengue cases was established in accordance with the aminotransferase levels assayed during the period of the disease, via the Dry Chemical method (Johnson \& Johnson ${ }^{\circledR}$ ). The reference levels for normality were: for men, AST up to $59 \mathrm{U} / \mathrm{L}$, ALT up to $72 \mathrm{U} / \mathrm{L}$; for women, AST up to $36 \mathrm{U} / \mathrm{L}, \mathrm{ALT}$ up to $52 \mathrm{U} / \mathrm{L}$. These cutoff values were established by the clinical analysis laboratory of the CRD, which is affiliated with the Brazilian Society of Clinical Analyses.

Hepatic involvement in these patients was evaluated as four grades: grade A - normal levels of aminotransferase; grade B - elevated aminotransferase, with increased levels of at least one of the enzymes; grade C - elevated aminotransferase, with the levels of at least one of the enzymes increased to more than three times the reference values; grade D - acute hepatitis, with aminotransferase levels increased to at least 10 times their normal values.

Virus isolation was attempted from acute phase serum specimens, without knowledge of their antibody content. C6/36 clone cells of Aedes albopictus were grown on Leibovitz medium (L$15)$, supplemented with $1 \%$ non-essential amino acids, $10 \%$ tryptose phosphate and $10 \%$ fetal calf serum. Sera were diluted $1 / 10$ in L-15 tissue culture medium and $0.05 \mathrm{ml}$ inoculated onto monolayers of cells in culture medium containing $2 \%$ fetal calf sera. This procedure was done at the Instituto Oswaldo Cruz [28]. Virus isolates were typed by indirect immunofluorescence assay (IFA), using serotypespecific monoclonal antibodies [29].

The data on the aminotransferase levels, positive serology for dengue, and clinical variables, was analyzed with the $\mathrm{X}^{2}$ test.

\section{Results}

Among the patients attended (3,850), 878 did not return to the CRD to request confirmation serology for the disease. There were 658 cases that were serologically negative for $\operatorname{IgM}$, while 2,314 cases of dengue were serologically confirmed due to positive IgM. Among these 2,314 patients with dengue, 729 were asymptomatic at the time of the exam and were attended after the $10^{\text {th }}$ day of the disease, and therefore they were not included in the laboratory analysis protocol for aminotransferase. Thus, 1,585 patients serologically positive for dengue who were symptomatic, or were attended between the first and the $10^{\text {th }}$ day of the disease, were evaluated via the protocol described above (Table 1).

The average age of the patients was 35.5 years $( \pm 16.3)$. Among these patients, 58.3\% (924) were female, $65 \%(1,030)$ were serologically negative for IgG (first infection), $91 \%(1,443)$ had a diagnosis of classic dengue and there were 142 cases (9\%) of hemorrhagic dengue fever (Table 2). The type 3 dengue virus was isolated in 12 cases by indirect immunofluorescence assay (IFA) and the type 1 dengue virus was found in only one patient, who had the classic form of the disease. Among the 12 cases of isolation of the type 3 dengue virus, eight patients had a diagnosis of DHF and four of classic dengue. Of the 1,585 dengue cases analyzed, no cases of encephalopathy or fulminating hepatitis were observed, and no death due to the disease occurred.

An alteration in AST level was seen in $63.4 \%$ and in ALT in $45 \%$ of the patients (Table 3). Both of these enzymes were normal in $34.8 \%$ of the patients (grade A); $44.5 \%$ had altered levels of at least one of the enzymes (grade B); $16.9 \%$ had at least one of the enzymes increased to three times its reference level (grade C) and $3.8 \%$ of the cases had acute hepatitis (grade D) (Table 2).

The average levels of AST and ALT were 93.3 U/L $( \pm 117)$ and $86.0 \mathrm{U} / \mathrm{L}( \pm 93.7)$, respectively. The average levels of AST and ALT were greater in DHF (127.1 U/ $\mathrm{L}$ and 100.2 U/L, respectively) than in classic dengue (89.8 U/L and 84.6 U/L, respectively) (Table 3). 
Table 1. Patients attended at the Dengue Reference Center from March to May 2002

\begin{tabular}{lc}
\hline Number of suspected dengue infections & $\mathbf{3 , 8 5 0}$ \\
\hline Patients who did not return for serological confirmation & 878 \\
negative for dengue IgM & 658 \\
Confirmed dengue cases asymptomatic at the time of the & 729 \\
exam or attended after the $10^{\text {th }}$ day of the disease & \\
Confirmed dengue cases analyzed & 1,585 \\
\hline
\end{tabular}

Table 2. Classification of dengue patients

\begin{tabular}{|c|c|c|c|c|c|}
\hline $\begin{array}{l}\text { Dengue type } \\
\text { Total }\end{array}$ & $\begin{array}{l}A \\
34.8 \%(551)\end{array}$ & $\begin{array}{l}\text { B } \\
44.5 \%(706)\end{array}$ & $\begin{array}{l}C \\
16.9 \%(268)\end{array}$ & $\begin{array}{l}\text { D } \\
3.8 \%(60)\end{array}$ & $\begin{array}{l}\text { Total } \\
100 \%(1,585)\end{array}$ \\
\hline \multicolumn{6}{|l|}{ Sex } \\
\hline Male & $47.8 \%(316)$ & $37.7 \%(249)$ & $11.3 \%(75)$ & $3.2 \%(21)$ & $41.7 \%(661)$ \\
\hline $\begin{array}{l}\text { Female } \\
\qquad \mathrm{p}<0.001\end{array}$ & $25.4 \%(235)$ & $49.5 \%(457)$ & $20.9 \%$ (193) & $4.2 \%(39)$ & $58.3 \%(924)$ \\
\hline \multicolumn{6}{|l|}{$\operatorname{IgG}$} \\
\hline Positive & $29.7 \%(165)$ & $51.2 \%(284)$ & $15.3 \%(85)$ & $3.8 \%(21)$ & $35 \%(555)$ \\
\hline $\begin{array}{l}\text { Negative } \\
\qquad p=0.001\end{array}$ & $37.5 \%(386)$ & $41.0 \%(422)$ & $17.8 \%(183)$ & $3.8 \%$ (39) & $65 \%(1030)$ \\
\hline \multicolumn{6}{|l|}{ Dengue } \\
\hline Hemorrhagic & $20.4 \%(29)$ & $47.2 \%(67)$ & $23.9 \%(34)$ & $8.5 \%(12)$ & $9 \%(142)$ \\
\hline $\begin{array}{l}\text { Classic } \\
\qquad \mathrm{p}<0.001\end{array}$ & $36.2 \%(522)$ & $44.3 \%$ (639) & $16.2 \%(234)$ & $3.3 \%(48)$ & $91 \%(1443)$ \\
\hline
\end{tabular}

Hepatic involvement in grades B, C and D was more common among women. There was greater hepatic injury among patients with sequential infection (IgG positive) and in cases of hemorrhagic dengue (Table 2).

\section{Discussion}

None of the patients included in the study reported active hepatic disease. All the patients with alterations in aminotransferase levels during the period of the study (1,034 patients, corresponding to $65.2 \%$ of the sample) had normal levels of this enzyme within 30 to 45 days after the initial evaluation. This leads us to believe that these abnormalities appeared while the patients were ill, possibly due to the aggression of the virus or hepatotoxicity of the treatment drugs.

The patients with 10-fold elevations in serum transaminase levels tested negative for IgM anti-HBc, IgM anti-HAV and HCV RNA; the latter by means of the polymerase chain reaction (PCR).

In the patients with grade $\mathrm{B}, \mathrm{C}$ and $\mathrm{D}$ hepatic involvement, elevation of AST occurred in most cases, either together with alterations in ALT levels or as a lone alteration (Figure 1). The ALT levels were normal in a greater percentage of cases $(55 \%)$ than were the AST levels (36.6\%), and the average AST level (93.3 U/L) was higher than that of ALT (86.0 U/L) (Table 
Table 3. Average aminotransferase levels in the 1,585 dengue patients, and correlation of the hepatic enzymes with degrees of hepatic alteration, sex, first infection and the hemorrhagic form of the disease

\begin{tabular}{lll}
\hline & AST & ALT \\
\hline $\begin{array}{l}\text { Mean } \\
\text { Levels }\end{array}$ & $93.3( \pm 117)$ & $86.0( \pm 93.7)$ \\
$\quad$ Normal & $36.6 \%(\mathrm{n}=580)$ & $55 \%(\mathrm{n}=873)$ \\
$\quad$ Abnormal $(<3 \mathrm{x})$ & $43.9 \%(\mathrm{n}=696)$ & $32.1 \%(\mathrm{n}=508)$ \\
$\quad 3 \mathrm{x}$ & $16.1 \%(\mathrm{n}=255)$ & $11.1 \%(\mathrm{n}=176)$ \\
$\quad>10 \mathrm{x}$ & $3.4 \%(\mathrm{n}=54)$ & $1.8 \%(\mathrm{n}=28)$ \\
Sex & & $82.2( \pm 89.6)$ \\
$\quad$ Male & $89.9( \pm 120.7)$ & $88.8( \pm 96.6)$ \\
$\quad$ Female & $95.7( \pm 114.2)$ & \\
$\quad \mathrm{p}=\mathrm{NS}$ & & $91.4( \pm 96.4)$ \\
IgG $\quad$ & $83.0( \pm 92.0)$ \\
$\quad$ Positive & $91.4( \pm 109.4)$ & \\
$\quad$ Negative & $94.3( \pm 121.1)$ & $100.2( \pm 99.2)$ \\
$\quad \mathrm{P}=\mathrm{NS}$ & & $84.6( \pm 93.0)$ \\
Dengue & &
\end{tabular}

NS = not significant; AST = aspartate aminotransferase; ALT = alanine aminotransferase.

Figure 1. Classification chart for hepatic involvement of the 1,585 dengue cases evaluated

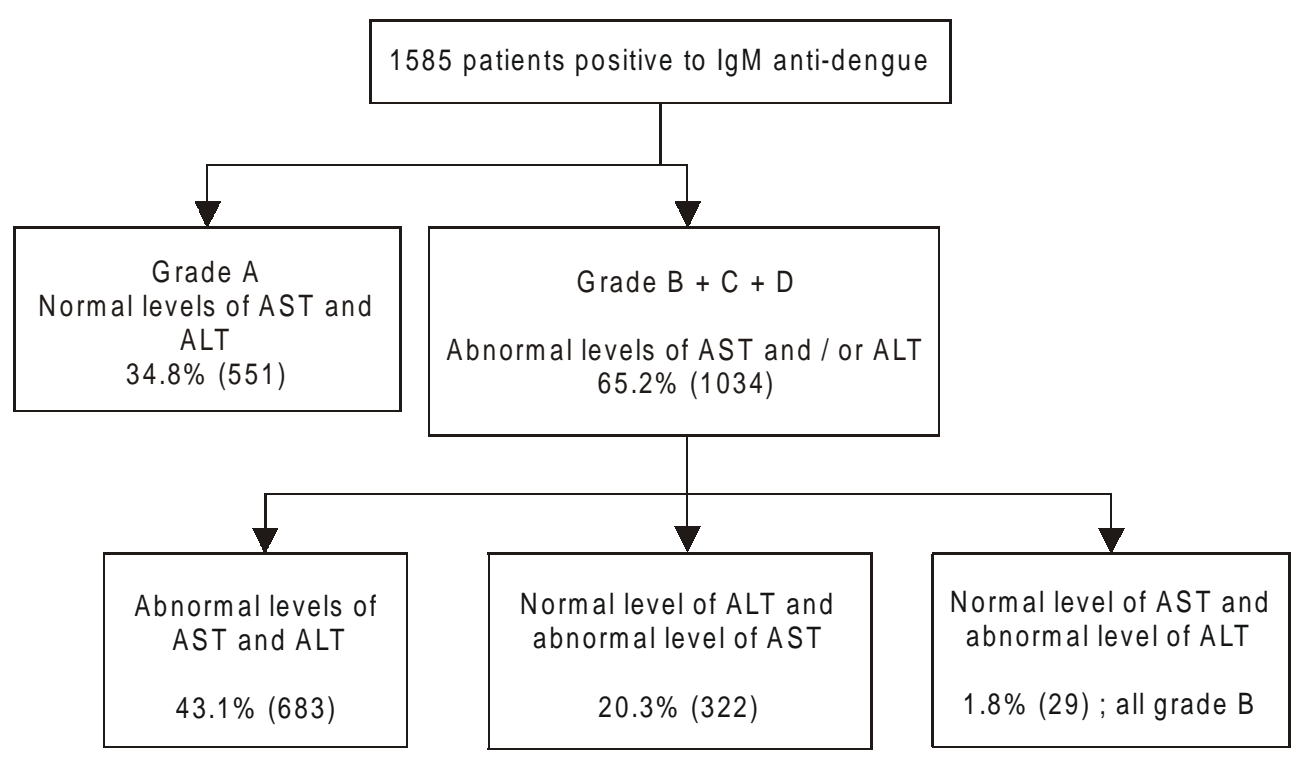


3). The frequency of extreme enzyme level elevations (greater than 10-fold) was greater for AST (3.4\%) than for ALT (1.8\%) (Table 3). Consequently, one characteristic of hepatic involvement during dengue virus infection was a greater elevation in AST than ALT levels. This information is useful for differential diagnosis of acute hepatitis caused by the $\mathrm{A}$. B or $\mathrm{C}$ viruses, in which this phenomenon is infrequently observed.

Dengue hemorrhagic fever may be associated with moderate degrees of hepatic functional abnormalities, and sometimes it shows characteristics typical of acute hepatitis.

Kuo et al. [26], in an evaluation of 270 dengue patients, observed abnormal levels of AST and ALT in $93.3 \%$ and $82.2 \%$, respectively. They reported that the rise in transaminase levels was mild to moderate in most cases, but reached 10 times above the normal upper limit for AST and ALT in $11.1 \%$ and $7.4 \%$ of the patients, respectively. They also reported that the elevation of AST levels was usually greater than for ALT, with a decrease to normal levels within three weeks. This may be due to the release of AST during myocyte damage in dengue infection.

Nimmannitya [4], in a study of 145 dengue patients, reported that $74 \%$ of the cases had normal levels of ALT, $18 \%$ had slightly elevated ALT levels and $8 \%$ had a significant increase in these values. He made no determination of AST levels.

In our study, liver damage was more frequent among females, affecting $49.5 \%, 20.9 \%$ and $4.2 \%$ of the women in grades B, C and D, respectively. Overall, women were more affected; with $74.6 \%$ presenting some degree of liver damage, and $4.2 \%$ had acute hepatitis (Table 2).

In a study of 37 cases of reactive hepatitis in DHF and DSS patients, a predominance of females was observed. It was also seen that the cases with marked thrombocytopenia and high blood concentration corresponded to those with the highest serum aminotransferase levels [22].

We noted that there was no difference in the percentage of acute hepatitis cases in patients with a first infection versus those who were reinfected (Table 2), thus demonstrating the virulence of the circulating sample.
There was no significant difference in the mean aminotransferase levels in males versus females and in the first infection versus reinfection groups (Table 3). It became evident that differences in aminotransferase levels are important and significant, depending on the severity of liver damage.

Liver damage was greater in patients with DHF; acute hepatitis (grade D) was diagnosed in $8.5 \%$ of these patients. The mean increases in AST and ALT were greater in the hemorrhagic form of the disease. WAHID et al., in a study of 50 serologically confirmed cases (25 cases of classic dengue and 25 of DHF), also found that the serum levels of AST and ALT were significantly greater among patients with the hemorrhagic form of the disease [25].

Mohan et al. evaluated 61 children with clinical suspicion of dengue, with 37 cases of classic dengue, 16 of DHF and 8 of DSS, and observed that $96 \%$ of the children had abnormal transaminase levels. These values were higher in the DHF and DSS [23].

Among the 142 DHF patients in our study, 63.2\% were classified as primary infection. This differs from observations made by Zagne et al. [30], in a study in Niterói, Rio de Janeiro, during the the DEN-2 virus epidemic; 55 of the 56 cases of hemorrhagic dengue were classified as reinfection.

All of these 142 hemorrhagic cases progressed with a low or normal blood sedimentation rate at the beginning of the clinical condition (before development of shock). This fact could be explained by the concentration of the blood that occurred during the hemorrhagic form of the disease, which might have slowed down erythrocyte sedimentation. This information could help with laboratory diagnosis of DHF. More detailed studies will be needed to in order to better determine the importance of this phenomenon.

In conclusion, dengue fever is usually associated with mild to moderate elevations of aminotransferase levels and, in most cases, with acute hepatitis. Liver damage was more frequent among women, patients with sequential infection and hemorrhagic cases. The disease course is usually self-limiting and we did not observe hepatic failure, but this may develop in some patients. Attention must therefore be given to the use of 
hepatotoxic drugs, which have the potential to aggravate liver damage in some cases of dengue.

The type 3 dengue virus was predominant in our study group and was found in more than $98 \%$ of the cases isolated in the 2002 epidemic in the state of Rio de Janeiro (Nogueira et al., unpublished). Genetic characterization has identified genotype III [21], which has been associated with DHF in Sri Lanka and India and DHF cases and deaths in Mexico and Central American countries [31].

\section{Acknowledgements}

We thank the Department of Health of the Municipality of Campos dos Goytacazes, for encouragement and financing that were fundamental for the creation and development of the Dengue Reference Center and the Plínio Bacelar clinical analysis laboratory, for the speed and reliability of their results. We also thank our colleague Thiago Ferreira de Souza, for his important contribution towards accomplishing this study.

\section{References}

1. Nogueira S.A. Dengue: artigo de revisão. Rev Pediatria Soperj 2001;2(1):22-8.

2. Souza L.J., Ronald C., Lopes A.C., et al. Aspectos clínicos da dengue: novos conceitos. Rev Bras Clin Terap 2002;28(2):46-52.

3. Ronald C., Souza L.J., Lopes A.C. Rev Bras Clin Terap 2001;27(4):168-75.

4. Nimmannitya S. Clinical spectrum and management of dengue haemorrhagic fever. SE Asian J Trop Med Pub Health 1987; 18(3):392-7.

5. Nimmannitya S. Dengue haemorrhagic fever in Thailand. SE Asian J Trop Med Pub Health 1987;18(3):291-4.

6. Tirado M.G.G., Flores G.K., González J.R.B. La emergencia de la fiebre hemorrágica del dengue en las Américas. Reemergencia del dengue. Rev Cubana Med Trop 1999;51(1):5-13.

7. Arias O.R., Pérez A.P., Bicet A.D., et al. Caracterización de pacientes con diagnóstico presuntivo de dengue en el brote epidémico del año 1997. Rev Cubana Med Trop 2001;53(1):24-7.
8. Westaway E.G., Brinton M.A., Gaidamovich S.Y., et al. Flaviviridae. Intervirology 1985;24:183-92.

9. Nogueira R.M.R., Miagostovich M.P., Schatzmayr H.G., et al. Virological study of a dengue type 1 epidemic in Rio de Janeiro. Mem Inst Oswaldo Cruz 1988;83(2):219-25.

10. Nogueira R.M.R., Miagostovich M.P., Lampe E., et al. Dengue epidemic in the State of Rio de Janeiro, Brazil, 1990-1991: co-circulation of dengue 1 and dengue 2 serotypes. Epidemiol Infect 1993;111:163-70.

11. Nogueira R.M.R., Miagostovich M.P., Schatzmayr H.G., et al. Dengue in the State of Rio de Janeiro, Brazil, 19861998. Mem Inst Oswaldo Cruz 1999;94(3):297-304.

12. Nogueira R.M.R., Miagostovich M.P., Filippis A.M.B., et al. Dengue type 3 in Rio de Janeiro, Brazil. Mem Inst Oswaldo Cruz 2001;96(7):925-6.

13. Department of Health of the State of Rio de Janeiro. Bulletin 2002, Rio de Janeiro, 2002.

14. Souza R.W., Cunha R.V., Miagostovich M.P., et al. An outbreak of dengue virus infection in the state of Ceará, Brazil. Mem Inst Oswaldo Cruz 1995;90(3):345-6.

15. Vasconcelos P.F., Menezes D,B,, Melo L.P., et al. A large epidemic of dengue fever with dengue hemorrhagic cases in Ceará State, Brazil, 1994. Rev Inst Med Trop São Paulo 1995;37:11-7.

16. Nogueira R.M.R., Filippis A.M.B., Coelho J.O., et al. Dengue virus infection of the central nervous system (CNS): A case report from Brazil. SE Asian J Trop Med Pub Health 2002;33:1,68-71.

17. George R., Liam C.K., Chua C.T., et al. Unusual clinical manifestations of dengue virus infection. SE Asian $\mathbf{J}$ Trop Med Pub Health 1988; 19(4):585-90.

18. Lum L.C.S., Lam S.K., George R., et al. Fulminant hepatitis in dengue infection. SE Asian J Trop Med Pub Health 1993;24(3):467-71.

19. Nimmannitya S., Thisyakorn U., Hemsrichart V. Dengue haemorrhagic fever with unusual manifestations. SE Asian J Trop Med Pub Health 1987;18(3):398-406.

20. Souza L.J., Lopes A.C., Bastos D.A. Icterícia na dengue hemorrágica: relato de três casos. Rev Bras Clin Terap 2002;28(5):198-201.

21. Miagostovich M.P., Santos F.B., De Simone T.S., et al. Genetic characterization of dengue virus type 3 isolates in the State of Rio de Janeiro, 2001. Braz J Med Biol Res 2002;35:1-4.

22. Díaz S.V., Martínez M.P., Saent-Félix F.G. Hepatitis reactiva por virus del dengue hemorrágico. Rev Cubana Med Trop 2001;53(1):28-31.

23. Mohan B., Patwari A.K., Anand V.K., et al. Hepatic dysfunction in childhood dengue infection. J Trop Pediatrics 2000;46:40-3.

24. Nguyen T.L., Nguyen] T.H., Tieu] N.T. The impact of dengue haemorrhagic fever on liver function. Res Virol 1997;148:273-7. 
25. Wahid S.F.S.A., Sanusi S., Zawawi M.M., et al. A comparison of the pattern of liver involvement in dengue hemorrhagic fever with classic dengue Fever. SE Asian J Trop Med Pub Health 2000;31(2):259-63.

26. Kuo C.H., Tai D.I., Chang-Chien C.S., et al. Liver biochemical tests and dengue fever. Am J Trop Med Hyg 1992;47(3):265-70.

27. Ministry of Health. Dengue: aspectos epidemiológicos, diagnóstico e tratamento. Editora MS: Brasília, 2002:1-21.

28. Igarashi A. Isolation of a Singh's Aedes albopictus cell clone sensitive to dengue and chikungunya viruses. J Gen Virol 1978; 40:531-44.

29. Gubler D.J., Kuno G., Sather G.E.,, et al. Use of mosquito cell cultures and specific monoclonal antibodies in surveillance for dengue viruses. Am J Trop Med Hyg 1984;33:158-65.

30. Zagne S.M.O., Alves V.G.F., Nogueira R.M.R., et al. Dengue haemorrhagic fever in the State of Rio de Janeiro, Brazil: a study of 56 confirmed cases. Trans Roy Soc Trop Med Hyg 1994;88:677-9.

31. Figueroa R., Ramos C. Dengue virus (serotype 3) circulation in endemic countries and reappearance in America. Arch Med Res 2000;31:429-30.

32. World Health Organization. Dengue hemorrhagic fever: diagnosis, treatment, prevention and control. $2^{\text {nd }}$ edition. Geneva: WHO, 1997:1-83.

33. Angibaud G., Luaute J., Laille M., et al. Brain involvement in dengue fever. J Clin Neuroscience 2001;8(1):63-5. 